\title{
Sustainable Ecological TOURISM Regional of Disaster ResPonse in Pacitan, East Java
}

\section{KAWASAN WiSATA EKOLOGIS BERKELANJUTAN TANGGAP BENCANA di Pacitan, Jawa Timur}

\author{
Yosafat Winarto $^{1 *}$, Wiwik Setyaningsih ${ }^{2}$, Sri Yuliani ${ }^{3}$ \\ Architecture Departement, Faculty of Engineering, Universitas Sebelas Maret ${ }^{1{ }^{*}}$ \\ yosafat_winarto@staff.uns.ac.id * \\ Architecture Departement, Faculty of Engineering, Universitas Sebelas Maret ${ }^{2}$ \\ Architecture Departement, Faculty of Engineering, Universitas Sebelas Maret ${ }^{3}$
}

\begin{abstract}
Pacitan Regency is an area that has a huge potential for tourism that is growing very rapidly. The beach has a beautiful natural landscape, as a natural geopark and gets wide publications through social media. The environment has the potential to threaten serious damage if the tourism area is not planned properly. Pacitan area is also an area with high risk of earthquake and tsunami natural disasters. Tourism development can adversely affect environmental and socio-cultural changes. Natural disasters can have a high risk of loss of life and material.

This research aims to produce a sustainability development planning concept, able to prosper the local community and be responsive to natural disasters. The research method uses a advocacyparticipatory paradigm and a Qualitative research strategies that combine grounded observation techniques and phenomenology. Research analysis uses SWOT to find problem solutions.

This research produced a sustainable ecological development concept and disaster response planning in the Pacitan tourism area. The concept emphasizes the socio-cultural and economy development of local communities and the natural environment preservation. The concept can be used as a guide to regional planning models and partial planning in Pacitan tourism areas on the future.
\end{abstract}

Keywords: sustainable development, tourism regional, response to disaster, Pacitan.

\section{PENDAhUluan}

Pacitan merupakan kabupaten yang terletak di ujung barat daya Jawa Timur, berbatasan dengan Jawa Tengah (Gambar 1). Wilayah Pacitan seluas $1.389 \mathrm{~km} 2$, yang 86 persennya adalah lanskap pegunungan karst. Kawasan Pacitan terdiri dari 166 desa dan 5 kelurahan. Populasi kawasan terdiri dari 583.857 jiwa dan memilik rasio gender 1,01 . Potensi kawasan geopark menyebabkan di Pacitan banyak terdapat pantai-pantai, tebing, karang, gua yang menarik para wisatawan untuk datang berkunjung.

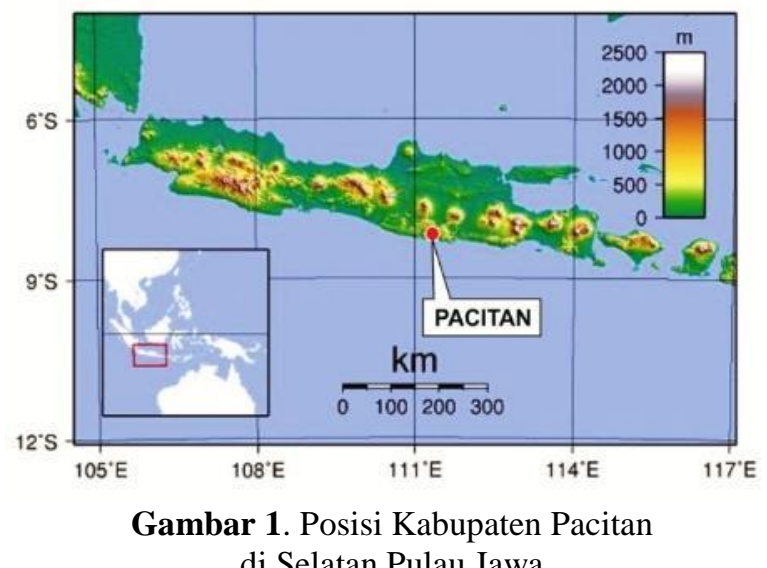

di Selatan Pulau Jawa 
Pengelompokan jenis destinasi wisata di kawasan wisata Pacitan dibagi menjadi beberapa kelompok. Kelompok destinasi wisata geopark yang meliputi : Pantai Srau, Pantai Klayar, Pantai Karang Bolong, Pantai Nampu, Pantai Watu Karung, Song Agung, Song Terus, Goa Gong, Goa Tabuhan, dan lain-lain. Kelompok destinasi wisata massal, meliputi Pantai Teleng Ria, Pantai Tamperan, Sumber air hangat Tirto Husodo, dan lain sebagainya. Kelompok destinasi wisata budaya dan minat khusus meliputi Pantai Tawang, Pantai Bawur, Pantai Taman, Pantai Soge, Gua Semopuro, Gua Papringan, Gua Petung, Gua Kambil, Markas Jendral Sudirman, makam Kanjeng Bayat, dan lain sebagainya. Destinasi wisata agro juga memiliki potensi untuk dikembangkan. Kabupaten Pacitan mengalami peningkatan kunjungan wisatawan yang sangat pesat pada kurun waktu beberapa tahun terakhir (Gambar 2).

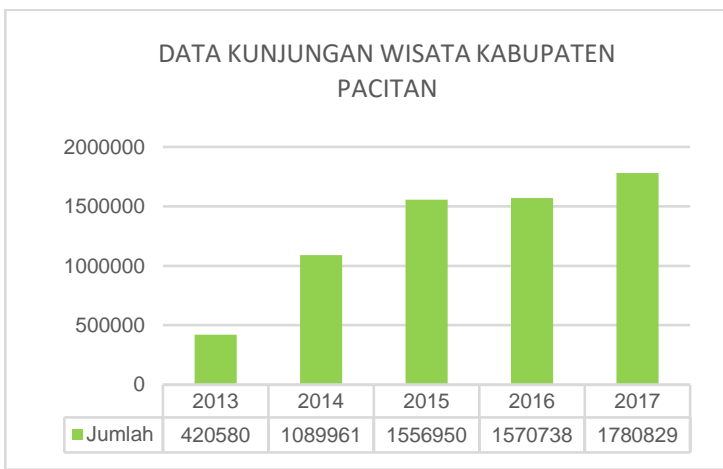

Gambar 2. Grafik peningkatan kunjungan wisatawan di Kabupaten Pacitan per tahun Sumber : PemKab Pacitan

Dari keseluruhan destinasi wisata di Pacitan hanya ada sembilan lokasi yang dikelola oleh Pemerintah Daerah. Sembilan obyek wisata itu adalah Pantai Klayar, Pantai Buyutan, Pantai Watu Karung, Pantai Srau, Pantai Taman, Pantai Pancer Door, Gua Gong, Gua Tabuhan, dan permandian air hangat Tirto Husodo. Obyek wisata yang lain dikelola oleh desa atau masyarakat lokal. Dari data terdapat tiga destinasi utama yang menarik pengunjung (Gambar 3). Pertama adalah Pantai Teleng Ria, Pantai Klayar, dan Gua Gong.

Peningkatan pesat kunjungan wisatawan banyak disebabkan oleh publikasi yang dilakukan masyarakat pengunjung melalui media sosial. Kemolekan alam Pacitan yang relatif masih secara alami menambah daya tarik wisatawan untuk datang dan melihat. Jarak yang relatif tidak terlalu jauh dari Yogyakarta sebagai kota wisata nasional dan kota Surakarta turut menarik minat para pengunjung. Pacitan dapat dituju sekitar tiga jam perjalanan baik dari kota Yogyakarta maupun kota Surakarta. Akses menuju ke kota Pacitan relatif baik, namun akses jalan yang menuju ke sebaran obyek destinasi wisata yang masih perlu ditingkatkan kualitasnya.

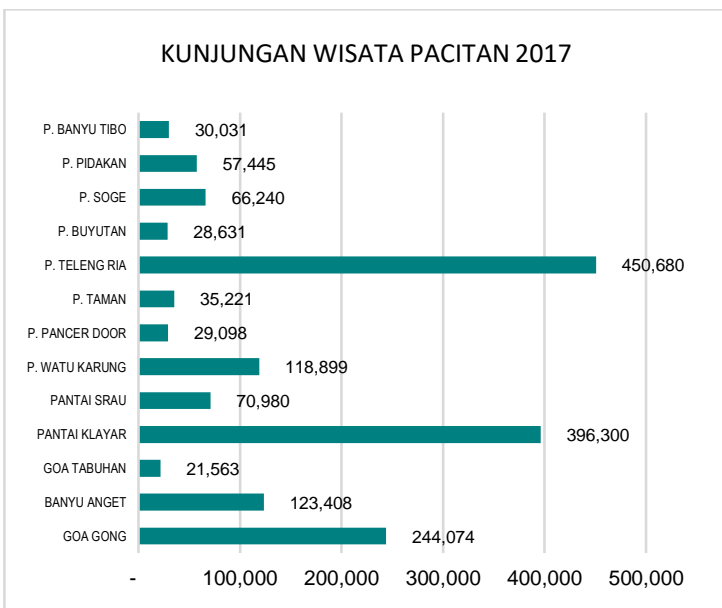

Gambar 3. Grafik kunjungan wisatawan di Pacitan 2017

Sumber: PemKab Pacitan

Kawasan wisata Pacitan sebagian besar adalah kawasan wisata pantai di selatan pulau Jawa. Garis pantai Pacitan merupakan wilayah yang terdekat dengan garis tumbukan atau subsiduksi lempeng Samudra Indo Australia dan lempeng Eurasia yang selalu aktif bergerak (Indriana, 2008) (Gambar 4).

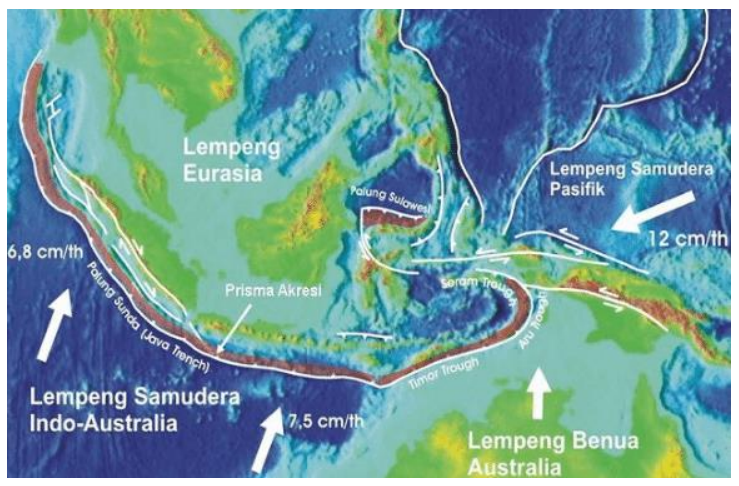

Gambar 4. Potensi bencana alam gempa bumi dan tsunami akibat subsiduksi lempeng di Selatan pulau Jawa

(sumber gambar : www.dosenpendidikan.com) 
Dengan kondisi geologis ini sepanjang garis pantai Pacitan memiliki potensi besar terjadi bencana alam gempa bumi dan bahkan tsunami. Masyarakat lokal perlu sadar akan potensi bencana alam tersebut. Model perencanaan harus mengakomodasi potensi ancaman alam agar ketika terjadi bencana alam, masyarakat telah siap dan meminimalkan jatuhnya korban jiwa dan harta benda.

Obyek wisata di Pacitan berkembang di seluruh wilayah kawasan Kabupaten Pacitan (Gambar 5). Bahkan banyak potensi wisata baru yang dikembangkan oleh masyarakat lokal.

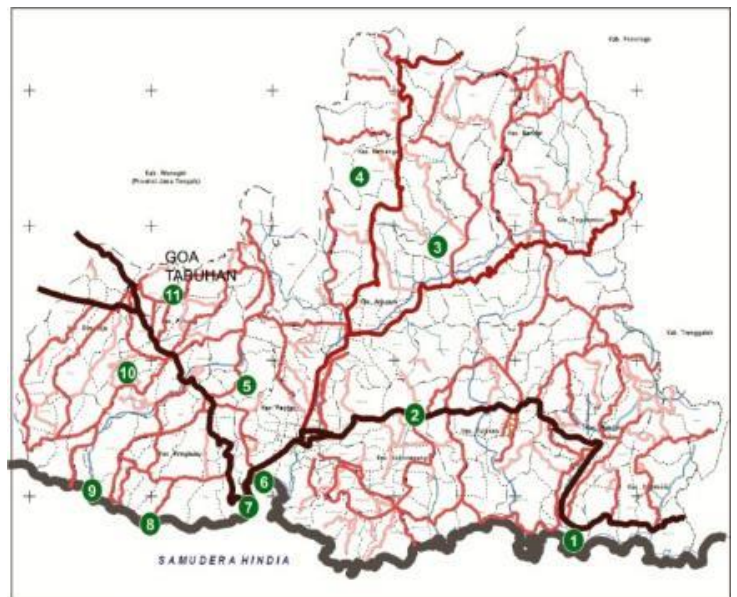

Gambar 5. Sebaran Potensi Obyek Wisata di Kawasan Pacitan : Pantai Sidomulyo (1), Desa Wonogondo (2), Tirto Husodo (3), Monumen Jendral Sudirman (4), Luweng Jaran (5), Pantai

Teleng Ria (6), TPI Tamperan (7), Pantai Srau (8), Pantai Klayar (9), Gua Gong (10) dan Gua Tabuhan (11)

Perlu kajian serius mengenai perkembangan kedatangan pengunjung ke kawasan wisata Pacitan yang begitu pesat. Studi mengenai potensi dan dampak di masa yang akan datang. Masyarakat lokal berpotensi mendapatkan keuntungan terbesar apabila industri pariwisata di desanya maju. Masyarakat lokal pula yang menjadi korban utama apabila kemajuan industri wisata mengorbankan kelestarian alam sekitar. Kemajuan industri wisata akan memiliki dampak positif terhadap ekonomi lokal. Namun industri pariwisata dapat pula melemahkan sosial dan budaya lokal serta merusak lingkungan kawasan. Dari total 48 lebih destinasi wisata di Kabupaten Pacitan hanya terdapat sembilan destinasi wisata yang dikelola oleh pemerintah daerah. Sisanya dikelola oleh masyarakat desa setempat. Destinasi yang khususnya dikelola masyarakat lokal ini perlu upaya pendampingan dan arahan agar pengembangannya tidak salah arah.

Penelitian ini bertujuan untuk membuat kajian konsep perencanaan berkelanjutan wisata ekologis yang tanggap bencana di kawasan wisata Pacitan. Sasaran jangka pendek yang diharapkan adalah untuk mempersiapkan perencanaan destinasi wisata parsial yang dapat dilakukan oleh segenap pemangku kebijakan dan pelaku wisata di kawasan Pacitan. Sasaran jangka menengah yang diharapkan adalah agar kemajuan wisata lokal baik yang dikelola oleh Pemerintah Daerah maupun desa dapat memberdayakan masyarakat lokal dan meningkatkan perekonomiannya, serta tanggap terhadap potensi bencana alam setempat. Sedangkan sasaran jangka panjangnya adalah agar kelestarian alam dan budaya lokal tetap lestari sehingga kawasan wisata tetap mampu menarik minat pengunjung dan mensejahterakan masyarakat lokal.

Potensi paradoksal terjadi pada kondisi seperti pada saat ini (Gambar 6). Ancaman yang cukup serius apabila kapitalisme melihat peluang potensi industri pariwisata di kawasan Pacitan. Kapitalisme dapat secara nyata mengeksploitasi potensi alam kawasan Pacitan untuk kepentingan keuntungan yang sebanyakbanyaknya.

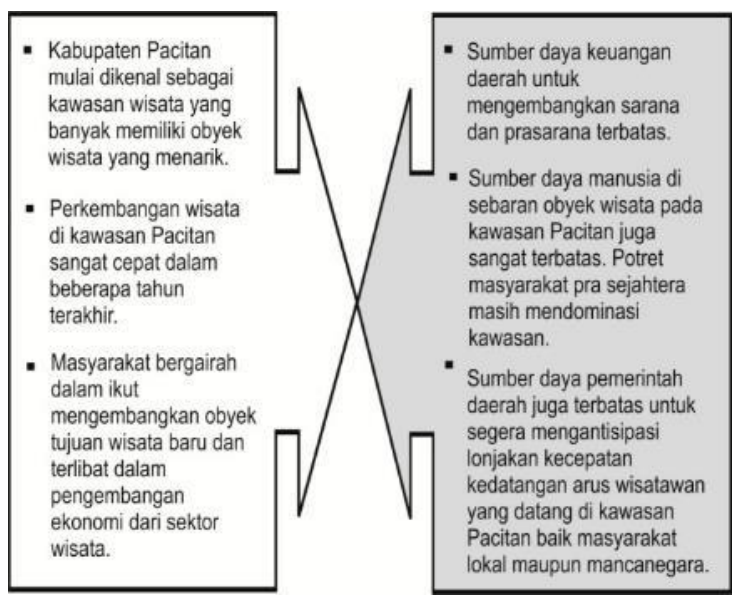

Gambar 6. Paradoks kondisi sekarang yang berpotensi menjadi masalah di kawasan wisata Pacitan

Hadirnya modal swasta akan menguasai sumber daya alam dan kesempatan masyarakat 
lokal untuk lebih berdaya di wilayahnya sendiri. Sistem ekonomi kapitalis tidak mendorong pembangunan berkelanjutan yang nyata. Minat kapitalisme hanya akan memperluas akumulasi modal dan bisnisnya (Eckersley, 2004). Kondisi demikian dapat menghadirkan paradoks pembangunan pariwisata daerah : wisata berkembang pesat, namun masyarakat hanya sebagai penonton. Masyarakat lokal tidak berdaya untuk mengelola sumber daya alam di lingkungannya. Pariwisata tidak mampu untuk mengangkat ekonomi masyarakat lokalnya.

Ditambah pula dengan kondisi geologis sepanjang garis pantai Pacitan yang memiliki potensi besar terjadi bencana alam gempa bumi dan tsunami. Masyarakat lokal perlu sadar akan potensi bencana alam tersebut. Konsep perencanaan harus mengakomodasi potensi ancaman alam agar ketika terjadi masyarakat siap, tanggap dan meminimalkan jatuhnya korban jiwa serta harta benda.

Pembangunan berkelanjutan dapat memenuhi kebutuhan kita hari ini tanpa kehilangan kemampuan generasi mendatang untuk memenuhi kebutuhan mereka (WCED, 1987). Konsep ini merupakan konsep ideal untuk diterapkan pada perencanaan pembangunan kawasan wisata di Pacitan. Terdapat tiga pilar utama penyangga pembangunan berkelanjutan, yaitu Pembangunan Ekonomi, Pembangunan Masyarakat dan Pembangunan Ekologis (Winarno, 2013) (Gambar 7). Generasi sekarang dapat mengelola dengan sebaikbaiknya sumber daya alam dan lingkungannya untuk kesejahteraan, juga memikirkan kelestarian sumber daya alam tersebut untuk generasi yang akan datang. Alam dan lingkungan yang meliputi sumber daya alam hayati, sosial dan budaya masyarakat lokal dapat terus lestari di masa yang akan datang.

Konsep pembangunan berkelanjutan memiliki nilai-nilai ekonomi, nilai-nilai moral dan nilainilai ekologi (Keraf, 2002; Elliot, 2006). Generasi sekarang memiliki tanggung jawab moral untuk generasi masa depan dan alam (Pawlowski, 2006) atau disebut sebagai "prinsip keadilan antargenerasi" (Hull, 2008).

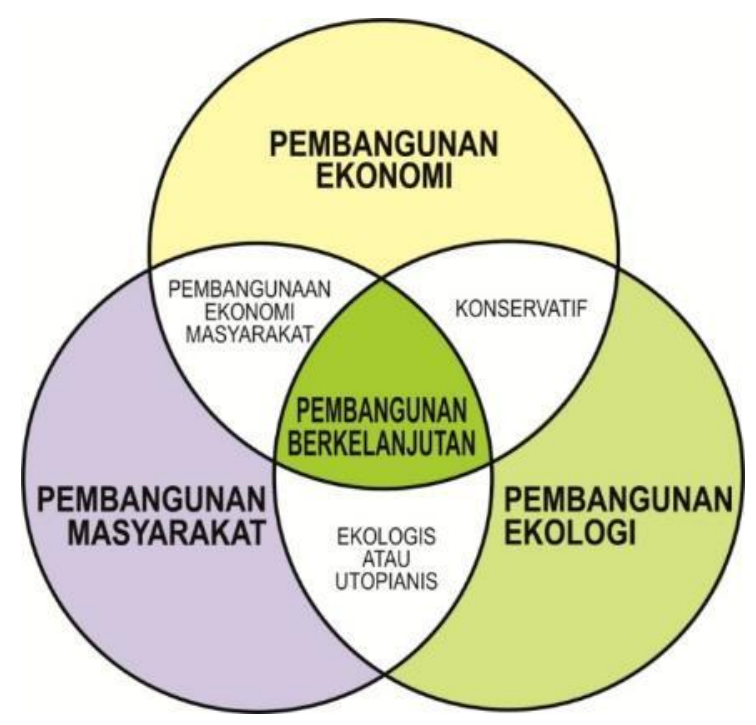

Gambar 7. Tiga pilar pembangunan berkelanjutan (Winarno, 2013)

Pembangunan berkelanjutan dapat menyelesaikan masalah paradoksal kapitalisme yang diuraikan pada pendahuluan atas. Kapitalisme bertolak belakang dengan tujuan agar masyarakat lokal yang mengelola sendiri sumber daya alamnya secara berkelanjutan. Sistem ekonomi kapitalis tidak mendorong pembangunan berkelanjutan yang nyata. Minat kapitalisme hanya akan memperluas akumulasi modal dan bisnisnya (Eckersley, 2004). Kapitalisme akan menyedot kemampuan sumber daya alam dan masyarakat lokalnya, dan akan pergi ketika alam dan lingkungan sudah tidak dapat lagi menjadi tambang investasinya. Kegagalan mengelola sumber daya alam akan berdampak sangat serius. Kegagalan menciptakan stabilitas di bidang lingkungan akan menyebabkan bencana yang lebih besar di masa depan (Stiglitz, 2006).

Konsep pembangunan keberlanjutan dari masyarakat, oleh masyarakat dan untuk masyarakat menjadi sebuah konsep ideal model perencanaan pembangunan berkelanjutan di kawasan wisata Pacitan. Namun pembangunan berkelanjutan di Indonesia menghadapi banyak kendala dengan masalah mendasar dalam kualitas kehidupan dan sumber daya manusia (Abdoellah, 2016).

Penelitian ini berupaya menjawab berbagai tantangan dan kendala dengan menghadirkan konsep perencanaan pembangunan wisata 
ekologis berkelanjutan yang tanggap pada potensi bencana alam.

\section{METODE}

Kajian pada penelitian ini dilakukan pada sembilan obyek destinasi wisata yang dikelola pemerintah daerah. Kesembilan destinasi tersebut adalah Pantai Buyutan, Pantai Klayar, Gua Gong, Pantai Watu Karung (Gambar 9), Pantai Srau (Gambar 10), Gua Tabuhan, permandian air hangat Tirto Husodo, Pantai Pancer Door, dan Pantai Taman.

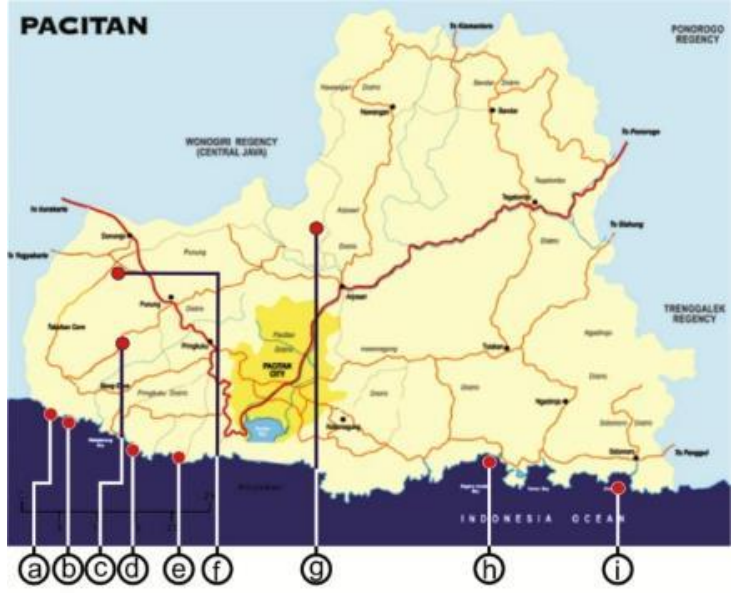

Gambar 8. Sebaran 9 obyek destinasi wisata Pacitan dalam penelitian Pantai Buyutan [a], Pantai Klayar [b], Gua Gong [c], Pantai Watu Karung [d], Pantai Srau [e], Gua Tabuhan [f], permandian air hangat Tirto Husodo [g], Pantai Pancer Door [h], dan Pantai Taman [i].

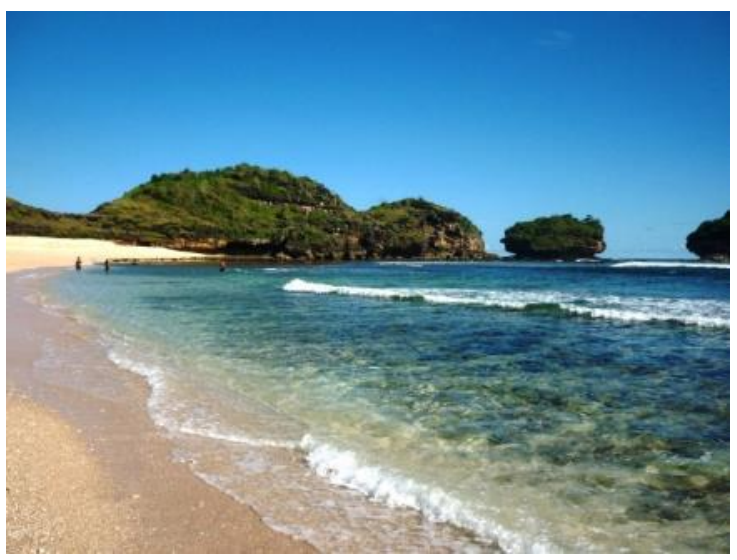

Gambar 9. Pantai Watu Karung

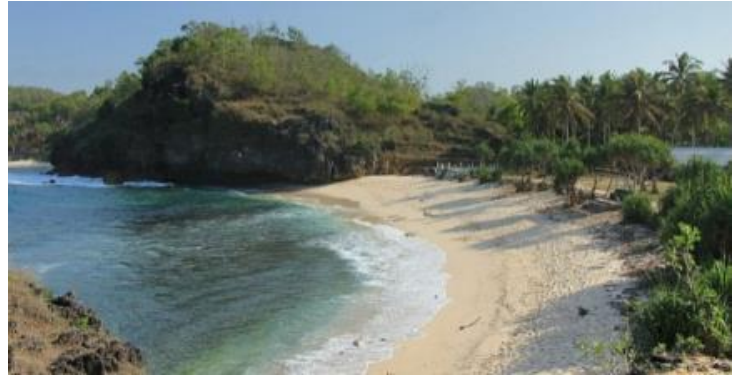

Gambar 10. Pantai Srau

Obyek penelitian tersebut dapat dijadikan sebuah model perencanaan kawasan wisata parsial yang terpadu. Sembilan obyek penelitian merupakan destinasi wisata yang banyak dikunjungi wisatawan di Pacitan, dan saat ini dikelola oleh pemerintah daerah Pacitan. Pemerintah daerah dapat menerapkan model kawasan wisata ekologis yang tanggap terhadap bencana yang dihasilkan dari penelitian ini di lapangan. Model dapat dikembangkan pada obyek destinasi wisata lain yang dikelola oleh desa atau komunitas masyarakat lokal.

Paradigma advokasi / partisipatoris (Creswell, 2013) dikembangkan dalam penelitian ini. Penelitian memiliki agenda misi reformasi yang diharapkan dapat memperbaiki kehidupan masyarakat lokal di kawasan wisata Pacitan baik secara ekonomi, sosial dan budaya. Penelitian juga memiliki misi agar masyarakat lokal sendiri yang mendukung pemerintah lokal dalam melestarikan daya dukung alam dan lingkungannya. Strategi penelitian dilakukan secara kualitatif dan deskriptif. Metode pengambilan data dan penelusuran masalah dilakukan dengan observasi grounded research, phenomenology dan studi kasus lapangan. untuk mengumpulkan data melalui observasi pemetaan spasial fisik, serta pemetaan budaya sosial-ekonomi, dan wawancara mendalam dengan tokoh masyarakat.

Data-data kuantitatif secara statistik yang diperoleh dari pemerintah daerah dikomparasikan dan dielaborasikan pada kondisi di lapangan, pada dua kondisi densitas pengujung yang berbeda. Pada kondisi sangat sepi pengunjung (low season) dimana hampir sama sekali tidak ada pengunjung dan pada kondisi puncak kedatangan pengunjung (peak season). Observasi pada saat sepi pengunjung 
dilakukan pada hari kerja di tengah minggu (weekday) dimana penelitian banyak mendapatkan data mengenai kondisi keseharian masyarakat setempat dan kawasan wisata. Observasi pada saat puncak kunjungan wisata dilakukan pada saat dimana secara kuantitatif data statistik terjadi lonjakan kunjungan wisata tertinggi dalam setahun. Waktu yang dilakukan pada observasi ini pada saat libur hari raya Idul Fitri di hari kedua. Peneliti dapat mengamati banyak hal terkait dengan daya dukung lingkungan, daya dukung sarana dan prasarana, perilaku pengunjung dan masyarakat setempat. Penelitian juga menggali aspirasi pengunjung dan masyarakat setempat melalui metode wawancara secara terbuka (open interview) kepada masyarakat lokal, pengunjung serta pemerintah daerah. Semua data didokumentasikan, diklasifikasikan dan dikodifikasikan untuk dianalisis hingga mendapatkan hasil yang dapat dipertanggungjawabkan.

Data-data yang terkumpul diklasifikasikan untuk dianalisis dengan metode SWOT. Teknik analisis SWOT dipilih karena dianggap mampu melihat persoalan dari empat sisi sekaligus, baik dari sisi positif maupun sisi negatifnya. Keempat sisi tersebut adalah sisi kekuatan (strengths), sisi kelemahan (weaknesses), sisi peluang (opportunities) dan sisi ancaman (threats). Analisis SWOT dapat digunakan secara tajam dan ampuh untuk menemukan langkah terbaik penyelesaian masalah (Fatimah, 2016). Hasil analisis SWOT dapat menjadi sebuah pedoman perencanaan kawasan wisata Pacitan yang ekologis berkelanjutan dan tanggap bencana di masa sekarang dan masa yang akan datang.

\section{HASIL DAN DISKUSI}

Hasil observasi dan penelitian lapangan secara mendalam pada kawasan wisata terdapat banyak faktor-faktor penting untuk dianalisis. Faktor-faktor tersebut baik berupa faktor-faktor positif maupu faktor-faktor negatif. Analisis SWOT diandalkan sebagai alat analisis yang mampu menghasilkan solusi dan berbagai strategi penyelesaian masalah di lapangan.

Pada tabel analisis SWOT (Tabel 1) disusun identifikasi faktor-faktor dari berbagai kekuatan (strengths), kelemahan (weaknesses), peluang(opportunities) dan ancaman (threats) dari kondisi yang sekarang ada di kawasan wisata Pacitan.

Tabel 1. Identifikasi SWOT

\begin{tabular}{|c|c|c|}
\hline \multirow{4}{*}{$\mathbf{S}$} & \multicolumn{2}{|c|}{ STRENGTH - kekuatan ( positif ) } \\
\hline & 1. & $\begin{array}{l}\text { Pacitan semakin dikenal sebagai kawasan } \\
\text { wisata yang menarik untuk dikunjungi. }\end{array}$ \\
\hline & 2. & $\begin{array}{l}\text { Peningkatan tajam kedatangan kunjungan } \\
\text { wisata baik wisatawan mancanegara } \\
\text { maupun wisatawan nusantara. }\end{array}$ \\
\hline & 3. & $\begin{array}{l}\text { Masyarakat lokal sangat bergairah untuk } \\
\text { ikut mengembangkan industri wisata } \\
\text { lokal. }\end{array}$ \\
\hline \multirow{3}{*}{$\mathbf{W}$} & \multicolumn{2}{|c|}{ WEAKNESSES - kelemahan ( negatif ) } \\
\hline & 1. & $\begin{array}{l}\text { Kemiskinan - potensi kualitas sumber } \\
\text { daya manusia yang perlu upaya serius } \\
\text { untuk dikembangkan. }\end{array}$ \\
\hline & 2. & $\begin{array}{l}\text { Kemampuan sumber daya manusia yang } \\
\text { kurang memadai untuk mengelola sumber } \\
\text { daya alam setempat }\end{array}$ \\
\hline \multirow{6}{*}{$\mathbf{O}$} & \multicolumn{2}{|c|}{ OPPORTUNITIES - peluang ( positif ) } \\
\hline & 1. & Potensi keindahan alam \\
\hline & 2. & Potensi sumber daya lingkungan \\
\hline & 3. & Potensi budaya masyarakat lokal \\
\hline & 4. & Keramahan masyarakat setempat \\
\hline & 5. & Potensi kerajinan lokal \\
\hline \multirow{5}{*}{$\mathbf{T}$} & \multicolumn{2}{|c|}{ THREATS - ancaman ( negatif ) } \\
\hline & 1. & $\begin{array}{l}\text { Kegagalan perencanaan awal yang } \\
\text { memicu banyak masalah }\end{array}$ \\
\hline & 2. & Kerusakan sumber daya alam \\
\hline & 3. & $\begin{array}{l}\text { Kapitalisme / kehadiran investor yang } \\
\text { mengambil alih pemberdayaan } \\
\text { masyarakat lokal untuk mengelola sendiri } \\
\text { kekayaan alamnya. }\end{array}$ \\
\hline & 4. & $\begin{array}{l}\text { Bencana alam yang menyebabkan korban } \\
\text { jiwa dan harta benda. }\end{array}$ \\
\hline
\end{tabular}

Tabel 1 menunjukkan faktor-faktor negatif pada kawasan. Faktor negatif tersebut berupa kelemahan utama (weaknesses) dan ancaman penting (threats) di kawasan wisata Pacitan. Faktor negatif tersebut menjadi perhatian dalam penelitian untuk dicarika solusi pemecahan masalahnya. 
Tabel 1 juga menunujukkan faktor-faktor positif dari kondisi dan situasi sosial, budaya masyarakat serta alam lingkungan kawasan wisata Pacitan. Faktor-faktor positif tersebut berupa kekuatan (strength) dan peluang (opportunities) yang terdapat pada masyarakat lokal dan lingkungan setempat. Penggalian dan elaborasi faktor-faktor positif tersebut diharapkan dapat menjadi strategi pemberdayaan masyarakat untuk dapat terlibat aktif dalam pembangunan wisata ekologis berkelanjutan yang tanggap pada potensi bencana alam.

Tabel 2 berupa kajian analisis SWOT untuk mencari solusi dari faktor-faktor negatif dan positif di kawasan wisata Pacitan. Faktor-faktor positif dapat menjadi sebuah strategi untuk menyusun dan mengembangkan gagasan untuk memperbaiki faktor-faktor negatif di kawasan wisata Pacitan.

Kedua faktor positif di kawasan wisata Pacitan, yaitu kekuatan (strengths) dan peluang (opportunities) dikaji untuk menemukan kebijakan utama arah perencanaan pengembangan kawasan wisata. Penelitian dapat menyimpulkan bahwa wisata lokal yang memiliki potensi besar untuk dikembangkan di kawasan Pacitan adalah wisata alam dan wisata budaya (Tabel 2 [a]). Pengembangan wisata alam dan wisata budaya harus melibatkan peran serta masyarakat lokal sebagai pemain utama (Tabel $2[b]$ ).

Masyarakat lokal harus dilibatkan secara penuh agar lebih berdaya di tempat tinggalnya sendiri. Pengembang wisata dari luar atau investor luar daerah perlu diberi batasan-batasan jelas mengenai aturan berinvestasi di kawasan wisata Pacitan. Dalam hal ini pemerintah daerah perlu segera menelurkan regulasi mengenai kebijakan investasi di kawasan wisata Pacitan. Masyarakat lokal perlu diberdayakan sebagai subyek di wilayahnya. Strategi ini membuat masyarakat lokal sendiri merasa memiliki dan bertanggung jawab atas kelestarian alam dan budayanya. Alam dan budaya setempat yang memberi kesempatan dan peluang besar perekonomian masyarakat lokal untuk kelangsungan kehidupannya. Masyarakat lokal sendiri akan menyadari bahwa daya tarik wisata lokalnya harus dijaga agar lestari supaya perekonomiannya berkelanjutan.
Tabel 2. Analisis SWOT

\begin{tabular}{|c|c|c|}
\hline & $\begin{array}{l}\text { OPPORTUNITIES } \\
\text { (peluang) } \\
\text { (positif) }\end{array}$ & $\begin{array}{c}\text { THREATS } \\
\text { (ancaman) } \\
\text { (negatif) }\end{array}$ \\
\hline \multirow{2}{*}{ 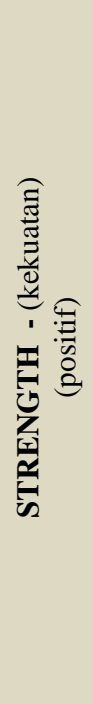 } & $\begin{array}{l}{[\text { a ] }} \\
\text { Pengembangan } \\
\text { potensi wisata lokal: } \\
\text { alam dan budaya }\end{array}$ & $\begin{array}{l}{[\mathbf{c}]} \\
\text { Perencanaan } \\
\text { terpadu untuk } \\
\text { mengembangkan } \\
\text { destinasi wisata di } \\
\text { Pacitan }\end{array}$ \\
\hline & $\begin{array}{l}\text { [ b ] } \\
\text { Pengembangan } \\
\text { kapasitas sumber daya } \\
\text { masyarakat lokal } \\
\text { untuk lebih } \\
\text { memberdayakan diri } \\
\text { terlibat dalam industri } \\
\text { pariwisata lokal. }\end{array}$ & $\begin{array}{l}\text { [d ] } \\
\text { Memberikan } \\
\text { wawasan } \\
\text { kesadaran } \\
\text { masyarakat lokal } \\
\text { tentang } \\
\text { pentingnya } \\
\text { pelestarian alam } \\
\text { dan upaya } \\
\text { mitigasi terhadap } \\
\text { bencana. }\end{array}$ \\
\hline 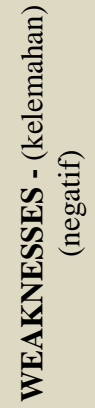 & $\begin{array}{l}\text { [ e ] } \\
\text { Pengembangan } \\
\text { pariwisata yang } \\
\text { terpadu di Pacitan } \\
\text { dapat menciptakan } \\
\text { peluang kerja yang } \\
\text { luas bagi masyarakat } \\
\text { lokal }\end{array}$ & $\begin{array}{l}\text { [ f ] } \\
\text { Konsep } \\
\text { pembangunan } \\
\text { berkelanjutan } \\
\text { untuk mengurangi } \\
\text { / menghilangkan } \\
\text { semua masalah } \\
\text { utama / konflik di } \\
\text { kawasan wisata di } \\
\text { Pacitan }\end{array}$ \\
\hline
\end{tabular}

Analisis juga mempertimbangkan potensi faktor kekuatan (strengths) untuk menyusun strategi mengurangi faktor ancaman (threats) pada kawasan wisata Pacitan. Analisis menyimpulkan bahwa diperlukannya sebuah perencanaan terpadu kawasan wisata Pacitan secara keseluruhan (Tabel 2 [c]). Model awal perencanaan terpadu dapat dilakukan pada sembilan obyek wisata di kawasan Pacitan yang dikelola oleh pemerintah daerah. Kesembilan oyek wisata tersebut adalah Pantai Klayar, Pantai Buyutan, Pantai Watu Karung, Pantai Srau, Pantai Taman, Pantai Pancer Door, Gua Gong, Gua Tabuhan, dan permandian air hangat Tirto Husodo.

Dengan segala potensi perkembangan wisatawan yang datang ke Pacitan maka bidang pariwisata akan memberikan kesejahteraan bagi 
masyarakat lokal. Pemerintah daerah dapat memberikan pendampingan kepada masyarakat lokal untuk memberikan sebuah kesadaran tentang pentingnya kelestarian alam dan budaya lokal yang ada di lingkungannya dan pemahaman akan potensi datangnya bencana alam yang bisa datang secara tiba-tiba (Tabel 2 [d]). Pemerintah Daerah menjadi penggerak utama dan menentukan kebijakan-kebijakan pelestarian dan mitigasi bencana di kawasan wisata Pacitan. Seluruh obyek wisata yang dikelola desa pun harus mengikuti aturan dan kebijakan yang ditetapkan oleh Pemerintah Daerah. Aturan dan kebijakan Pemerintah Daerah tersebut mengarahkan agar masyarakat lokal sendiri taat pada regulasi demi kelestarian dan keamanan dari bencana alam.

Analisis selanjutnya adalah kajian faktor negatif kelemahan (weaknesses) dengan mengelaborasikan faktor positif peluang (opportunities). Analisis memberikan hasil bahwa pengembangan kawasan secara terpadu di kawasan wisata Pacitan akan menciptakan banyak peluang dan kesempatan baru di bidang lapangan kerja bagi masyarakat lokal (Tabel 2 [e]). Pariwisata dapat menjangkau berbagai lini dan bidang kehidupan. Perencanaan terpadu mengarah pada peluang terciptanya lapangan kerja yang seluas-luasnya bagi masyarakat lokal. Potensi yang dapat dikembangkan adalah pariwisata dengan penekanan pada pelestarian alam, pelestarian budaya lokal, serta mitigasi potensi bencana.

Analisis juga mempertemukan kedua faktor negatif di kawasan penelitian, yaitu faktor kelemahan (weaknesses) dan faktor ancaman (threats) di kawasan wisata Pacitan (Tabel 2 [f]). Elaborasi dari kedua faktor negatif tersebut dengan mempertimbangkan faktor-faktor positif di kawasan menghasilkan sebuah resume analisis konsep sistem perencanaan terpadu. Perencanaan kawasan wisata di Pacitan secara keseluruhan menggunakan prinsip pembangunan ekologis berkelanjutan yang tanggap bencana. Konsep ini disimpulkan menjadi sebuah konsep yang paling tepat untuk mengurangi bahkan menghilangkan semua potensi konflik dan paradoks masalah yang ada di kawasan wisata Pacitan.

\section{KESIMPULAN}

Penelitian menyimpulkan beberapa hal pokok yang dapat diimplementasikan di kawasan wisata Pacitan untuk menjadi dasar perencanaan pembangunan untuk masa depan. Pembangunan perkelanjutan sebagai sebuah strategi utama perencanaan kawasan wisata. Pendekatan utama melalui tiga pilar utama pembangunan berkelanjutan, yaitu pembangunan yang berbasis pada pembangunan sumber daya masyarakat lokal, pembangunan ekonomi yang berpihak pada pengembangan perekonomian masyarakat lokal dan pelestarian ekologis untuk meningkatkan daya dukung alam dan mitigasi bencana alam. Kesimpulan konsep perencanaan kawasan wisata Pacitan dapat diuraikan secara lebih terperinci menjadi empat strategi. Pertama, perencanaan pembangunan sosial berbasis masyarakat lokal. Masyarakat ditempatkan sebagai subyek utama perencanaan pembangunan. Proses membangun gagasan dan aspirasi dalam perencanaan kawasan wisata perlu mengajak masyarakat untuk duduk bersama, menyampaikan pendapat dan aspirasinya. Masyarakat diajak untuk ikut memiliki dan berkepentingan terhadap semua program pembangunan yang direncanakan dan akan dilaksanakan untuk pengembangan kawasan wisata di lingkungannya. Setiap kebijakan pengembangan regulasi, sarana ataupun prasarana melibatkan unsur masyarakat. Pemerintah Daerah juga perlu mengajak masyarakat lokal dalam komunikasi bersama-sama untuk menginformasikan dan mensosialisasikan strategi, tahap dan proses pembangunan yang akan direncanakan. Dengan demikian masyarakat akan merasa ikut berkepentingan terhadap semua program pembangunan yang akan dilaksanakan oleh pemerintah daerah. Masyarakat lokal sendirilah yang nantinya secara inisiatif akan ikut menjaga dan memelihara hasil-hasil pembangunan karena merasa ikut memiliki dan sesuai dengan kebutuhan masyarakat.

Pendekatan kedua adalah perencanaan pembangunan ekonomi masyarakat lokal. Pemberantasan kemiskinan secara struktural di berbagai bidang dengan strategi pemberdayaan masyarakat lokal untuk secara lebih mudah mengakses pendapatan dan memperluas peluang pekerjaan di sektor pariwisata, budaya 
lokal dan kerajinan masyarakat. Prioritas pembangunan juga mengutamakan kebutuhan mendasar masyarakat seperti ketersediaan air bersih, energi yang terjangkau, permukiman layak, ketersediaan fasilitas kesehatan serta sarana dan prasarana pendidikan. Dengan terpenuhinya kebutuhan dasar, maka prasyarat dasar untuk melangkah menuju masyrakat sejahtera telah memadai. Masyarakat juga lebih siap untuk mengembangkan sumber daya dirinya hingga untuk generasi yang akan datang. Pola produksi dan konsumsi masyarakat juga diharapkan dapat dikembangkan untuk menopang keberlanjutan. Pengembangan ekowisata salah satu yang dapat diandalkan untuk meningkatkan ekonomi dan pemberdayaan kemandirian ekonomi masyarakat lokal. Potensi kerajinan masyarakat berupa batik tulis, batu akik, dan lain sebagainya perlu dikembangkan baik kualitas maupun diversifikasinya. Pemerintah Daerah dapat melakukan kajian khusus dalam rangka pengembangan kerajinan masyarakat lokal yang mendukung pariwisata. Industri kerajinan untuk sourvenir dan industri kuliner masih terbuka peluang bagi masyarakat di kawasan wisata Pacitan. Strategi penataan kawasan wisata Pacitan secara arsitektural dilakukan dengan mengimplementasikan prinsip arsitektur ekologis melalui pola zonifikasi dan desain bangunan penunjang dengan langgam dan kekhasan arsitektur lokal (Yuliani, 2018). Pendekatan ketiga adalah penyelamatan dan perlindungan ekosistem. Kawasan wisata Pacitan memiliki keindahan alam yang menawan perlu dilestarikan. Masyarakat juga perlu dilibatkan sebagai pemain dan penjaga utama ekosistem. Pemerintah Daerah perlu memberi pemahaman kepada masyarakat di kawasan wisata bahwa melestarikan alam berarti menjaga keberlangsungan kehidupan dan ekonomi masyarakat setempat. Ketika ekosistem rusak maka wisatawan akan menurun atau bahkan hilang. Perlindungan ekosistem pantai juga memberikan lingkungan pantai yang selalu indah, lestari dan aman. Upaya lain adalah penelitian tentang pengembangan perkebunan masyarakat dan perkebunan lokal yang berkelanjutan di kawasan karst dan di sebagian besar wilayah Pacitan untuk melestarikan ekosistem alam dan sumber daya air. Perkebunan atau hutan desa selain untuk melindungi sumber daya air juga dapat untuk meningkatkan kesejahteraan masyarakat lokal.

Dalam strategi pengembangan wisata pantai melalui pendekatan arsitektur ekologi di Pacitan, daerah tersebut memiliki potensi untuk dikembangkan sebagai tujuan pariwisata berkelanjutan. Pendekatan ekologi arsitektur secara berkelanjutan memiliki beberapa keuntungan dan keterkaitan dalam pola masalah yang terkait dengan ekosistem ramah lingkungan yang terkait dengan perencanaan infrastruktur yang mempertimbangkan keberlangsungan alam di masa depan. Konsep pengembangan kawasan wisata pantai harus lebih memperhatikan dan menjaga kondisi karakteristik lokal yang alami secara terpadu dan berkelanjutan.

Pendekatan keempat adalah perencanaan pembangunan dengan pertimbangan mitigasi bencana alam. Mitigasi mengarahkan kepada perencanaan yang memberikan tata kawasan ekologis dan tata bangunan yang aman serta kemudahan evakuasi bagi masyarakat dan wisatawan di kawasan wisata apabila terjadi bencana alam baik gempa bumi, tsunami, badai, banjir, erupsi gunung berapi ataupun tanah longsor. Mitigasi bencana alam meliputi manajemen resiko bencana alam, zonifikasi daerah rawan bencana, alokasi titik kumpul dan pengembangan struktur-konstruksi tradisional arsitektur lokal yang tahan gempa.

Hasil akhir tersebut adalah formulasi yang diharapkan menjadi konsep perencanaan kawasan wisata ekologis berkelanjutan yang tanggap terhadap bencana alam di Pacitan, Jawa Timur. Studi dapat dikembangkan pula menjadi usulan bagi Pemerintah Daerah dalam menyusun regulasi bagi terciptanya kawasan wisata ekologis berkelanjutan yang tanggap terhadap bencana alam di Pacitan, Jawa Timur.

\section{UCAPAN TERIMA KASIH}

Ucapan terima kasih sebesar-besarnya kepada Universitas Sebelas Maret (UNS) dan LPPM UNS (Lembaga Penelitian dan Pengabdian Masyarakat Universitas Sebelas Maret Surakarta) atas hibah dan penyaluran pendanaan pada penelitian ini. Penelitian ini dilaksanakan dengan dukungan pendanaan penelitian melalui Dana Anggaran PNBP (Penerimaan Negara Bukan Pajak) Universitas 
Sebelas Maret (UNS) Surakarta tahun anggaran 2018 berdasarkan SK Rektor Nomor 259/UN27/HK/2018 dan surat kontrak nomor 543/UN27.21/PP/2018.

\section{REFERENSI}

Abdoellah, Oekan. S (2017). Ekologi Manusia dan Pembangunan Berkelanjutan, Jakarta : PT Gramedia.

Creswell, John. W (2013). Research Design, Pendekatan Kualitatif, Kuantitatif dan Mixed, Yogyakarta : Pustaka Pelajar.

Eckersley, R. (2004). The Green State Rethinking Democracy and Sovereignty. London: The MIT Press.

Fatimah, Fajar Nur'aini Dwi (2016). Teknik Analisis SWOT. ogyakarta:QUADRANT.

Haifani, Akhmad Muktaf (2008). "Manajemen Resiko Bencana Gempa Bumi" dalam Proceeding Seminar Nasional IV SDM Teknologi Nuklir. ISSN 1978-0176 Yogyakarta.

Hull, Z. (2008). Sustainable Development : Premises, Understanding and Prospects, Sustainable Development. Vol. 16, hal. 73-80.

Indriana, Rina Dwi (2008). "Analisis Sudut Kemiringan Lempeng Subduksi di Selatan Jawa Tengah dan Jawa Timur Berdasarkan Anomali Gravitasi dan Implikasi Tektonik Vulkanik" dalam jurnal Berkala Fisika ISSN : 1410 - 9662. Vol 11. No.3 : 89-96.

Keraf, A. Sonny (2002). Etika Lingkungan. Jakarta:Penerbit Buku Kompas.

Keraf, A. Sonny (2014). Filsafat Lingkungan Hidup, Alam sebagai Sebuah sistem kehidupan. Yogyakarta : PT Kanisius.

Pawlowski, A (2008). How Many Dimensions Does Sustainable Development Have ? Sustainable Development. Vol.16 : 81-90.

Stiglitz, J.E. (2006). Making globalization Work. New York : Northon \& Company.

Tondobala, Linda (2011). "Pemahaman Tentang Kawasan Rawan Bencana dan Tinjauan Terhadap Kebijakan dan Peraturan Terkait" dalam Jurnal Sabua ISSN 2085-7020. Vol.3, No.1: 58-63.

Yuliani, Sri; Setyaningsih, W \& Winarto, Y (2018). "Strategi Penataan Kawasan Pantai Klayar Pacitan Sebagai Destinasi Pariwisata Berkelanjutan Dengan Prinsip
Arsitektur Ekologis" dalam Jurnal Ruas E-ISSN 2477-6033 P-ISSN 1693-3702. Volume 16 No. 2 : 1-12.

Winarno, Budi (2013). Etika Pembangunan. Yogyakarta:CAPS.

(2016). Rencana Induk Pembangunan Kepariwisataan kabupaten Pacitan Tahun 2016-2025. 